\title{
La representación de los vientos en el claustro de la catedral de Pamplona: notas para su estudio
}

\author{
María Dolores llorens González
}

Las primeras representaciones conocidas de los vientos fijaban su número en cuatro, al igual que las estaciones, las partes del mundo o los elementos de la naturaleza, y su imagen se remonta al arte helenístico y romano, aunque la idea de personificarlos está ya en los autores griegos ${ }^{1}$. El paso al arte cristiano se produjo a través del arte clásico.

La forma de representar los vientos ha sido tradicionalmente, una figura humana soplando, o sólo la cabeza, o incluso a veces ésta era de animal. Otra interpretación añade a la cabeza que sopla una trompa, cuerno o caracola. La primera fórmula de las apuntadas fue la preferida en la antigüedad, mientras que la segunda la escogió la miniatura bizantina, pasando de allí al arte italiano del siglo $\mathrm{XIV}^{2}$.

En un sentido cosmológico los vientos en número de cuatro se colocan en los ángulos de la superficie terrestre conforme a la concepción antigua reflejada en la Biblia que da forma cuadrada a la tierra. Así es como aparecen en mapas antiguos y también por ejemplo en el tapiz de la Creación de la catedral de Gerona. En él los vientos se representan en las cuatro enjutas del rectángulo que inscribe el círculo central ${ }^{3}$.

\footnotetext{
' Homero los enumera en la Odisea: Boreas, Céfiro, Euro y Notos.

2 Raymond VAN MARLE, Iconographie de l'art profane au Moyen Âge et à la Renaissance, Nueva York 1971, 2 vols., vol. II, pág. 294 y ss.

3 En el tapiz de Gerona los vientos están representados según la concepción homérica, como figuras humanas aladas en hombros y tobillos, insuflando dos cuernos y sobre un odre según el texto mitológico que cuenta que Ulises recibio del rey de los vientos, Eolo, a todos ellos encerrados en un odre. Están en relación con la creación, flotando como elementos bienhechores.
} 
En general, los vientos simbolizan un principio activo o violento y, en sentido bíblico, son el soplo o espíritu del Creador. Por lo tanto cuando se incluyen en los mapas se pueden entender unidos a la doctrina de la creación ${ }^{4}$.

A esto alude el texto bíblico de Henoc, capítulo 18:

“Vi los depósitos de todos los vientos, y vi que por ellos Dios adornó lo creado y vi los cimientos de la tierra. Vi incluso la piedra angular y los cuatro vientos que sostienen la tierra y el firmamento del cielo. Vi como los vientos extienden como un velo lo alto del cielo y como se mantienen entre el cielo y la tierra, son las columnas del cielo. $\mathrm{Vi}$ los vientos que hacen girar el cielo..." ${ }^{5}$

No es este el único caso en que los vientos aparecen en la Biblia, pues son nombrados en numerosas ocasiones y con diversos sentidos. Como mensajeros ${ }^{6}$, con sentido maléfico $y$ negativo $^{7}$, profético $y$ apocalíptico ${ }^{8}$ o, como simples puntos cardinales. Este último significado direccional ha sido utilizado a menudo desde la antigüedad. Vitruvio en Génesis.

4 Curiosamente los vientos no aparecen en el momento de la creación en el libro del

5 Texto recogido en Champeaux y Sterck, Introducción a los símbolos, Madrid 1984, pág. 87-89. Para simbología ver también Chevalier y GHeERBRANT. Dictionnaire des symboles, Paris 1969, pág. 791 y J. A. Perez RIOJA, Diccionario de símbolos y mitos, Madrid 1971, pág. 417-418.

6 Salmos 103,4: “Tiene por mensajeros a los vientos y por ministros llamas de fuego".

Salmos 148,8: “El fuego, el granizo, la nieve, la niebla, el viento tempestuoso, que ejecutan sus mandatos".

7 Entre otros sirvan como ejemplos los siguientes textos: Exodo, 10,13: “Moisés tendió su cayado sobre la tierra de Egipto, y Yavé hizo soplar sobre la tierra el viento Solano durante todo el dia y toda la noche. A la mañana, el viento Solano habia traido la langosta".

En Job 27,21 se abatía contra el hombre culpable: "Se arrebata el viento Solano y se lo lleva, y le arranca lejos de su hogar".

8 Jeremías 49,35: "Así dice Yavé Sebaot: Yo romperé el arco de Elam, el fundamento de su fuerza. Yo desencadenaré contra Elam los cuatro vientos de los cuatro confines del cielo. A todos estos vientos los dispersaré y no habrá nación que no vea llegar a ella a los fugitivos de Elam".

Apocalipsis 7,1-4: «Después de esto vi cuatro ángeles que estaban en pie sobre los cuatro ángulos de la tierra, y retenían los cuatro vientos de ella para que no soplase viento alguno sobre la tierra, ni sobre el mar, ni sobre ningún árbol. Vi otro ángel que subía del naciente del sol, y tenía el sello de Dios vivo, y gritó con voz fuerte a los cuatro ángeles, a quienes había sido encomendado dañar a la tierra y al mar, diciendo: No hagáis daño a la tierra, ni al mar, ni a los árboles, hasta que hayamos sellado a los siervos de nuestro Dios en sus frentes". 
su tratado De Architectura cita la torre de los vientos de Atenas en la que se esculpieron ocho imágenes de ocho vientos situados en la dirección del movimiento de los mismos. Dicha torre es de forma octogonal en mármol blanco situada al norte de la Acrópolis y construida por Antonio de Cyrrhus en el siglo । a. C. Cada uno de sus lados mira en dirección de uno de los ocho vientos. Sirvió también como cuadrante solar y reloj hidráulico. Ocho genios, emblemas de los vientos aparecen esculpidos en bajorrelieve.

"A algunos les parece, y dixeron que los vientos eran quatro. Del oriente equinocial el "Solano". Del mediodia el "Austro". Del occidente equinocial el "Favonio". Del septentrion el "Septentrión". Pero los que más diligentes los buscaron, dixeron ser ocho los vientos.

Principalmente cierto Andronico Cyrrhestes el cual puso por ejemplo en Atenas una torre de mármol ochavada, y en cada lado, u ochavo de la torre hizo esculpidas las imágenes de cada viento, cada uno contra su movimiento, sobre la cual torre hizo una meta, es pináculo o chapitel y sobre el cimborio puso un tritón de metal que tenía en la mano derecha una vara alzada, y assi lo imaginó, para que con el viento que corria y sobre la imágen del viento que soplaba tuviese puesta la vara.

Assi que estan asentados desta manera. Entre Solano y Austro de la parte del oriente Hyberno "Euro". Entre Favonio y Septentrión de la parde de occidente Hyberno, el viento "Africo". Entre Favonio y Septentrión "Cauro" al cual muchos Ilaman Coro. Entre Solano y Septentrión "Aquilón"»"

No es raro el conocimiento del texto de Vitruvio pues tuvo una amplia difusión en la Edad Media en la que consta que se siguieron realizando copias y concretamente durante los siglos XIII y XIV ${ }^{10}$.

A los cuatro vientos principales de los cuatro puntos cardinales se les fueron añadiendo más hasta llegar a ocho, como hemos visto en Vitruvio, o incluso doce subdivisiones que fueron adpotadas por autores como Plinio, Beda, Honorio de Autun, Vicente de Beauvais y San Isidoro de Sevilla.

9 Libro I, cap. IV.

10 L. Cervera Vera, El códice de Vitruvio hasta sus primeras versiones impresas, Madrid 1978, pág. 62. 
Si bien la tradición de los nombres de los vientos se repite a través de los siglos, existen algunas variantes en la nomenclatura y localización de los mismos. Por esto, de los autores antes mencionados, uno nos interesa más que todos los demás. San Isidoro de Sevilla, al estar más cerca de nuestro propósito de relacionar su obra con lo representado en Pamplona, como un ejemplo más de la conexión entre texto e imagen. La gran autoridad concedida a aquella y su lectura en la Edad Media hacen posible este hecho.

Es en dos de las obras de San Isidoro donde aparece recogida la cuestión de los vientos, en De Natura Rerum y en las célebres Etimologias. En la primera de anterior redacción que la segunda, explica los fenómenos naturales y sus causas con interpretaciones alegóricas, siendo fundamental durante varios siglos para todo sabio astrónomo o meteorólogo ${ }^{11}$.

También Lorente afirma que «por medio de la obra de San Isidoro se introdujo en el occidente cristiano la costumbre de emplear la rosa de los doce vientos, que se conservó durante toda la Edad Media. Los marinos, en cambio, usaban al menos desde el siglo Xvı, la actual y su división en 16 o 32 rumbos" ${ }^{12}$.

Así escribe San Isidoro en ese tratado:

“El primer viento cardinal es el "Septentrión", un viento frío de nieve, él sopla directamente del norte, produce fríos secos y nubes áridas. Se le llama también Aparctias. El "Circius" es llamado también Thrascias; viene de la derecha del Septentrión, provoca la caída de la nieve y la formación del granizo. El "Aquilón" es un viento llamado también Boreas, que sopla de lo alto del cielo; helado, seco y sin lluvia no dispersa las nubes pero las oscurece. Por esta razón él personifica al diablo pues reseca los corazones de los paganos con el frío de la maldad. El segundo viento cardinal es el "Subsolanus", llamado también Apeliotes, él viene del lado del oriente, y es un viento templado. El "Vulturnus"llamado también Caecias, está a la derecha del Subsolanus; él evapora y deseca todo. El "Eurus", que viene de la izquierda del Subsolanus, riega el oriente con sus nubes.

El tercer viento cardinal, el de la región meridional, es el "Auster", llamado también Notus; sopla bajo, húmedo, cálido y bochornoso, produce grandes nubes y lluvias muy abundantes; es igualmente el que

" Jose María LORENTE, "Los nombres de los vientos, según San Isidoro de Sevilla", Anales de la Sociedad Española de Meteorología, vol. II, 1928, pág. 93-94.

12 LORENTE, obra citada, pág. 94. 
abre las flores. El "Euroauster" es un viento cálido que sopla a la derecha del Auster. El "Euronotus" es un viento templado y cálido que sopla a la izquierda del Auster.

El cuarto viento cardinal es el Zéfiro, llamado también "Favonius", que sopla del fondo de Occidente; él detiene el rigor del invierno con su gratísima vuelta y hace crecer las flores. El "Africus", que se llama Lips, viene de la derecha del Zéfiro, engendra las tempestades y las lluvias, provoca los choques de las nubes, los zumbidos del trueno, la aparición de los relámpagos y los rayos. El "Corus" llamado también, Argestes, sopla de la izquierda del Favonio; cuando se da el cielo está nuboso en Oriente y sereno en la India" ${ }^{13}$.

Pasemos ahora, tras los textos, a lo esculpido en el claustro de la Catedral de Pamplona.

En las crujias norte, este y oeste se han figurado nueve vientos en igual número de claves por grupos de tres. Todos, excepto uno, están identificados por sus nombres que aparecen en el círculo exterior de la clave sobre la figura propiamente dicha del viento. El tipo escogido de representación es uno aunque con alguna variación, como se apuntará, y que consiste en una media figura humana soplando una trompa. De las tres claves del lado norte, dos de ellas (figuras 2 y 3 ) representan figuras de frente de las que sólo se ven la cara, hombros y brazos que sostienen el instrumento que soplan, la trompa; en la tercera (fig. 1) se encuadra una media figura entre hojarasca soplando igualmente una trompa sostenida entre las manos. En los tres casos las figuras tienen una abundante y alborotada cabellera.

En el lado este también son tres medias figuras las representadas (en el caso del viento de la fig. 4 es casi entera) con cabellos revueltos (figs. 5 y 6) y soplando una trompa en dos ocasiones (figs. 4 y 5 ) mientras que en el ejemplo de la figura 6 sólo sostiene el instrumento musical

13 Cap. XXXVII «De nominibus ventorum». La traducción es nuestra y se ha utilizado el texto de la edición de Jacques FonTAINE, Traité de la Nature, Burdeos 1960. En las Etimologias, libro XII, cap. 11 "Sobre los vientos": Cuatro son los principales vientos: el "Subsolano", que sopla de oriente; el "Austro" del mediodía; el "Favonio", de occidente; y del "Septentrión", el viento que lleva este mismo nombre. Cada uno de ellos tiene, a su vez, otros dos vientos de su misma procedencia. El Subsolano tiene, por el lado derecho, el "Vulturno», y por el izquierdo, el «Euro"; a la derecha del austro sopla el "Euroaustro", y a la izquierda, el "Austroafrico"; el Favonio tiene el "Africo" a su derecha y el "Coro" a su izquierda; y, finalmente, el Septentrión tiene por su derecha al "Cierzo" y por su izquierda al «Aquilón». Estos son los doce vientos que recorren con sus aires el globo terráqueo. 
entre sus manos sin soplarlo, aunque curiosamente se ha destacado el aire que hipotéticamente saldria del mismo, en el caso de estarlo utilizando, por el dibujo de unas líneas verticales, igual que en los otros casos que sí se insufla la trompa. Es ésta la única clave de la serie de los vientos en la que no se sopla la trompa, quizás por eso y por una mala lectura de la inscripción, Uranga la interpretó como el rio Ebro, cuando el nombre responde a Eurus, un viento del este ${ }^{14}$.

También hay otra excepción, anteriormente señalada, en la figura 4 $y$ es que carece de inscripción, aunque su identificación resulte fácil, como se verá más adelante.

En lo que respecta al lado oeste, las tres representaciones son bastante parecidas variando únicamente el color y la posición de la trompa. Aquí solo una cabeza de abundante cabellera sopla una trompa que tiene metida en la boca, llenando todo el espacio de la clave, rodeándola una inscripción con el nombre correspondiente (figs. 7, 8 y 9).

Como se puede apreciar, el tipo iconográfico es muy similar en los nueve casos, salvo las ligeras variaciones señaladas, con el denominador común de la figura humana y el instrumento musical de la trompa. Es decir, la forma tradicional de representación. También están todas policromadas, aunque ésto puede ser un repinte posterior a su ejecución, predominando el color azul para los fondos y túnicas y el dorado para las inscripciones. En lo que respecta a la trompa es el instrumento más representado en la catedral de Pamplona dentro de la gran variedad y profusión de elementos musicales que existen en ella ${ }^{15}$ como muestra de la importancia que se le dio a este arte a lo largo de la historia en Navarra.

La colocación en el conjunto del claustro es un dato importante, siendo la misma en cada ala, esto es el centro de la crujía, puestas correlativamente y respetando la derecha o la izquierda del viento principal como se escribe en los textos.

14 Uranga e INIIguez, Arte medieval navarro, Pamplona 1973, 5 vols., Vol. IV, pág. 233, lam. 60 c. María Antonia DEL BURGo, La catedral de Pamplona, León, Everest, 1977, pág. 61. Sigue a Uranga y habla del cuerno de la abundancia por donde fluye el Ebro.

15 Clara Fernández LadReda, lconografía musical de la catedral de Pamplona, Pamplona 1985. La autora contabiliza ocho trompas omitiendo el ejemplo de la figura 1, por lo que harian un total de nueve. También dice que este instrumento acompaña la representación de los ríos del claustro pero no es así, ningún instrumento musical se representa con los ríos. 
Es evidente el sentido direccional empleado en Pamplona como una rosa de los vientos, pues según su orientación se han colocado los mismos. Así en el lado norte están Circius por dos veces y Aquilón, en el este Subsolanus, Eurus y un tercero sin nombre que podría corresponder a Vulturnus y en el oeste Africus, Favonius y Chorus. Faltan los del lado sur donde es posible que se cayeran o fueran sustituidos por un cambio posterior de programa, puesto que se puede decir que los ciclos representados en el resto del claustro, en general, son muy completos, por to que cabe suponer que estuviera pensado esculpir también otros tres vientos en el lado meridional.

Si comparamos esta nomenclatura con los nombres incluidos en el texto de San Isidoro, vemos que se corresponde casi totalmente, con lo representado en Pamplona, solamente en el lado norte se ha figurado por dos veces el viento Circius, quizas por error, omitiéndose a Septentrio y dando el lugar de éste a Aquilón. Por otro lado viento, este último, muy aludido en la Biblia resultando posiblemente su nombre más familiar.

En lo que respecta al lado este, que como habiamos dicho hay una clave que carece de inscripción, según la denominación del texto isidoriano se podría identificar con Vulturnus (fig. 4).

Si se acepta la teoria de que existió un programa iconográfico completo de la representación de los doce vientos en las cuatro alas del claustro de la catedral de Pamplona, se puede concluir, en resumen, que se recogen los nombres aportados por Vitruvio (ocho) más las cuatro subdivisiones agregadas por San Isidoro, lo que hace un total de doce, por lo que cabe suponer la identidad tanto del que carecía de inscripción en el lado este (Vulturnus) como de los que faltan en el lado sur como Austro, Euroaustro y Euronotus. Se constituiría asi una especie de rosa de los vientos. Ésta fue representada en numerosas ocasiones en manuscritos medievales complicándose en época románica con la inclusión de otros personajes y adquiriendo un carácter más abstracto y complejo que en Pamplona no esta presente ${ }^{16}$. Existe también un deseo claro de individualizarlos al ser todos distintos. Otro tanto ocurría en la torre de los vientos de Atenas donde se personificaron jóvenes imberbes y viejos barbudos alternados.

Igualmente se puede advertir un sentido de interpretación cosmográfica al estar acompañada la representación de los vientos, de la serie de

16 Jurgis BALtRuSAITIS, “Roses de vents et roses de personnages à l'époque romane" Gazette des Beaux Arts, 2, 1938, pág. 265-276. 
los meses del año y de los ríos del paraíso. Estos últimos también faltan, como en el caso de los vientos, en el lado sur, lo que corroboraría el cambio de programa antes aludido. Los rios se esculpen en las claves de intersección de las bóvedas norte-oeste y norte-este, faltando en los ángulos del sur con el este y el oeste. El ciclo de los meses del año, sin embargo, está completo (sólo junio ha desaparecido) y se localiza en el lado norte y oeste.

Anteriormente se apuntó la importancia concedida, de forma deliberada, a la ubicación de los vientos en el centro mismo de la crujia respetando así su dirección exacta. Pues bien, esto se constata y subraya en el lado norte donde los vientos, para quedar situados correctamente, se entremezclan con los meses del año interrumpiendo la serie.

En cuanto al estilo, son de ejecución más notable las figuras del lado norte y este (figs. 1 a 6 ), sobresaliendo el modelado de los rostros con la expresión tan marcada de los grandes ojos almendrados y las rizadas y alborotadas cabelleras. Sin embargo en el lado oeste (figs. 7 a 9) el relieve más plano y tosco que en las anteriores nos habla de otro maestro cuya ejecución es de menor calidad que la del primero. Estas mismas características se dan en otras representaciones del claustro, lo que nos indica los diferentes momentos constructivos y decorativos por los que pasó la obra claustral navarra.

El claustro gótico de la catedral de Pamplona fue erigido entre el final del siglo XIII y el XV, siendo su momento de mayor auge constructivo el siglo XIV y más concretamente el período en que ocupó la sede iruñense el obispo Arnaldo de Barbazán (1315-1355), gran impulsor de las obras ${ }^{17}$. A esta época pertenece la mayor parte de la decoración esculpida que es rica en contenido y calidad. La representación de los vientos se podría incluir en esta fase cronológica y decorativa del claustro de la catedral de Pamplona constituyendo uno de los motivos iconográficos más interesantes de los allí figurados.

17 Para la biografía de este prelado ver José GoÑ GaZTAMBIDE, Historia de los obispos de Pamplona, II, Pamplona 1979. 


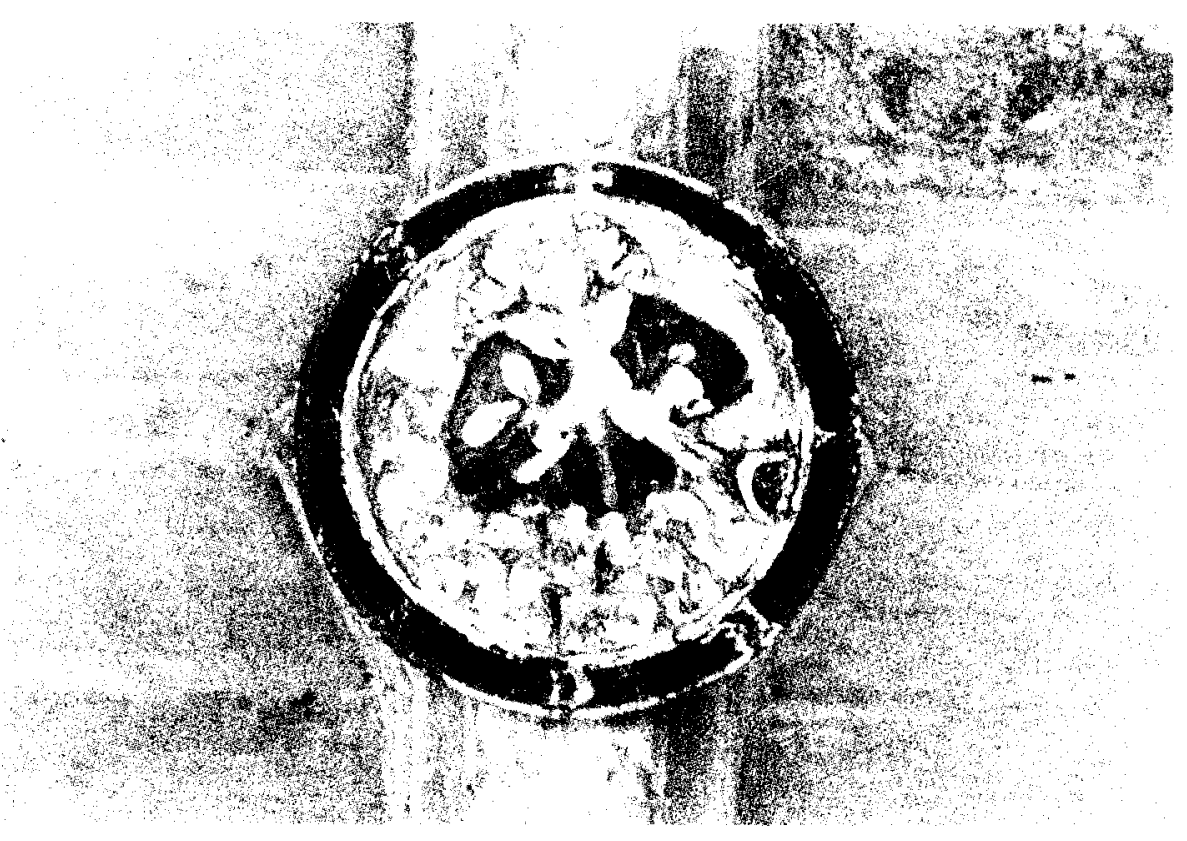

Fig. 1. Viento Circius.

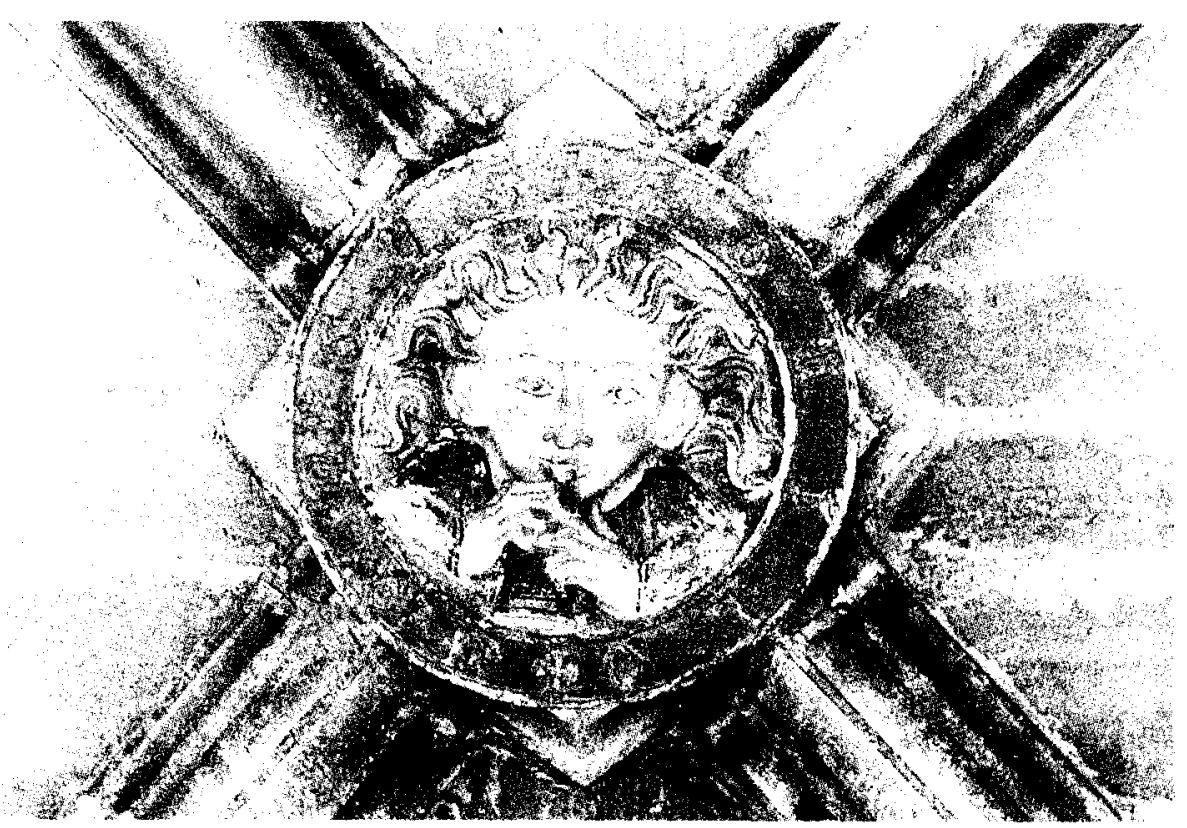

Fig. 2. Viento Aquilon. 


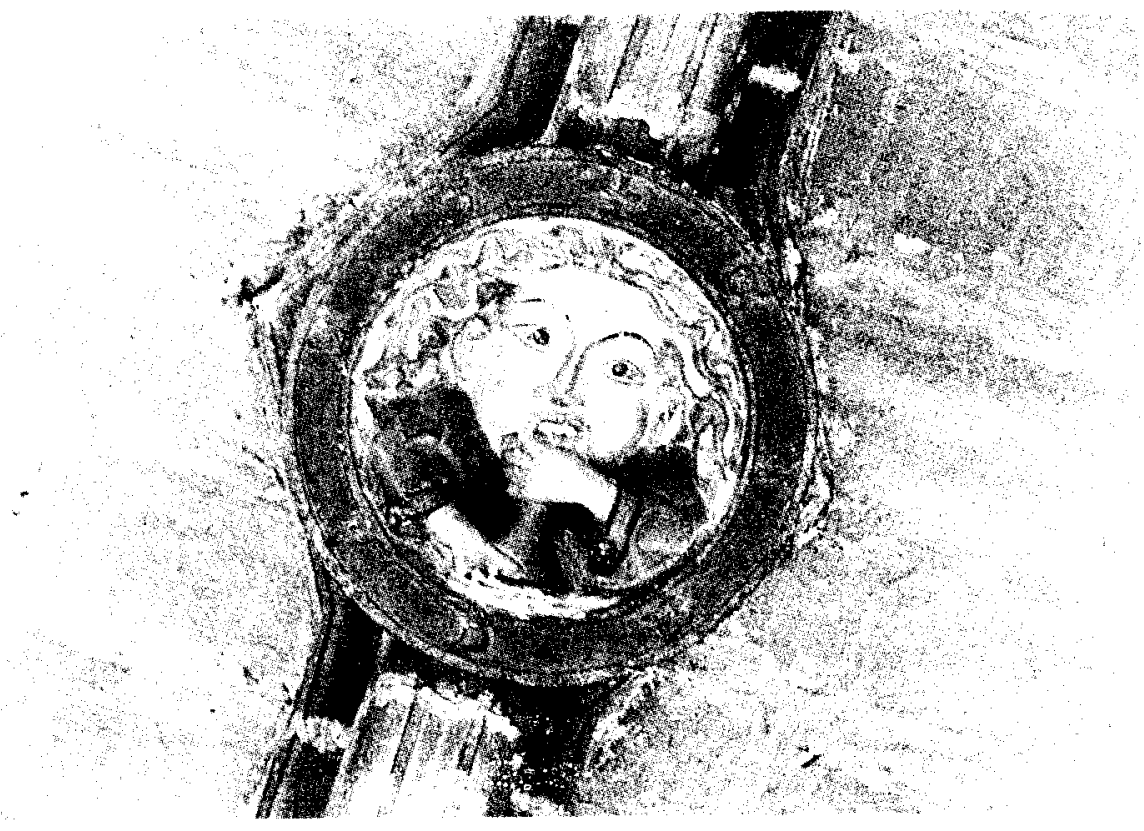

Fig. 3. Viento Circius

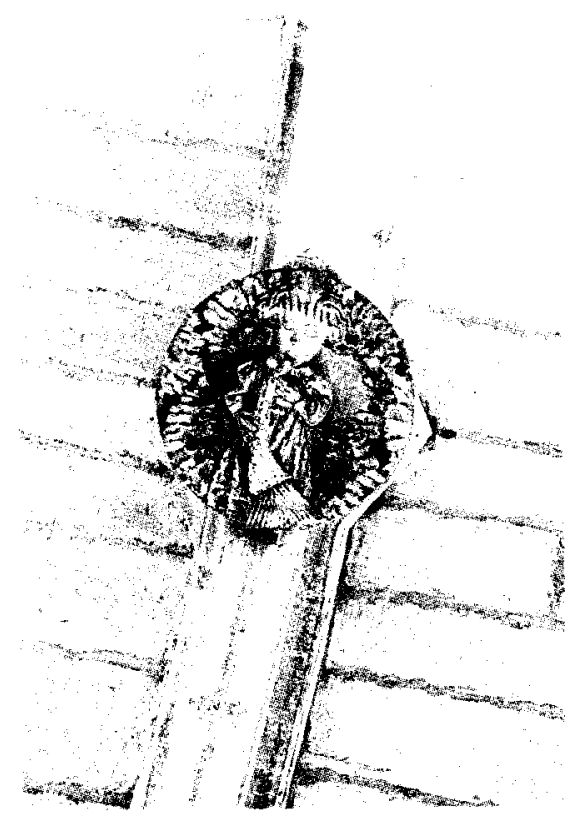

Fig. 4. Viento ¿Vulturnus? 


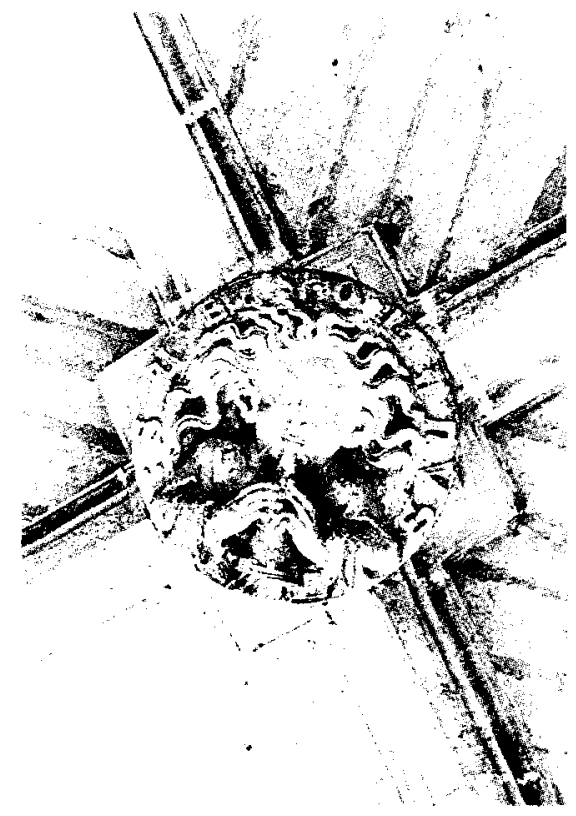

Fig. 5. Viento Subsolanus.

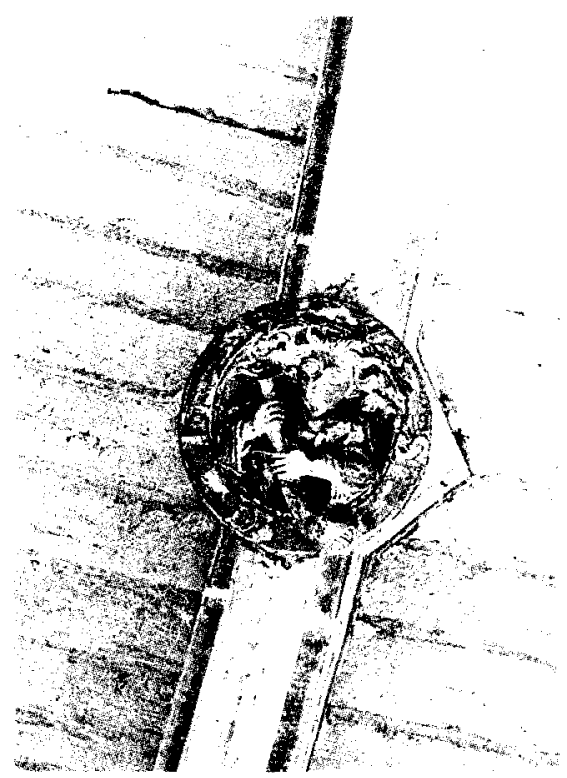

Fig. 6. Viento Eurus. 


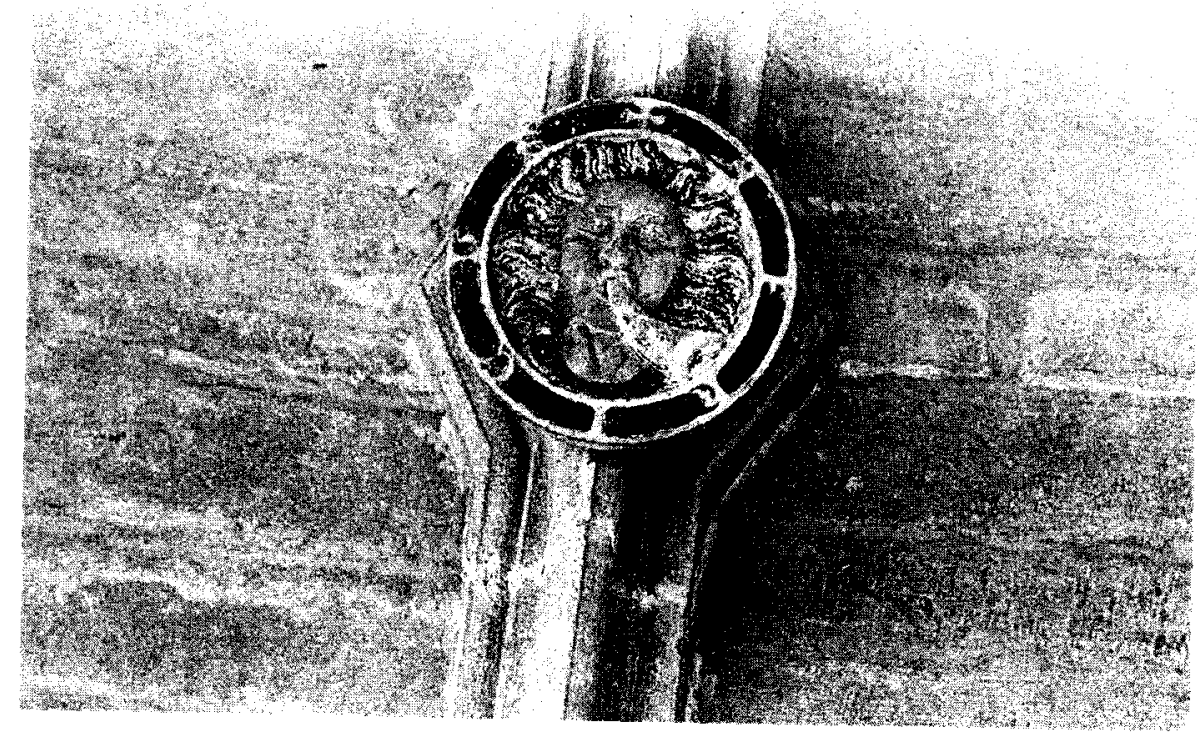

Fig. 7. Viento Africus.

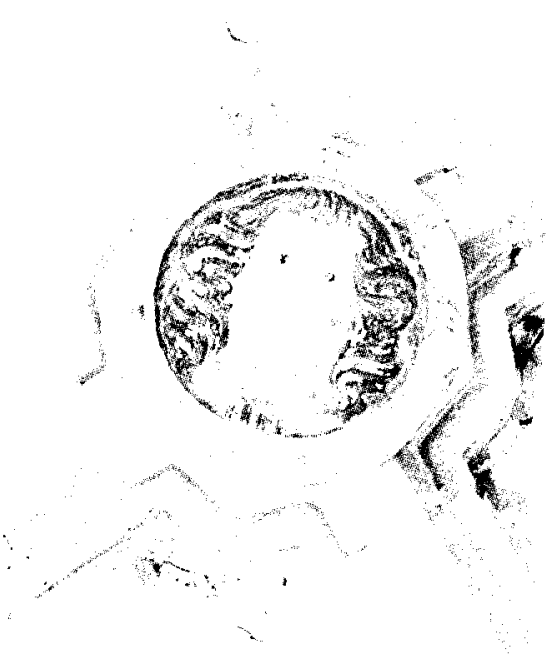

Fig. 8. Viento Favonius.

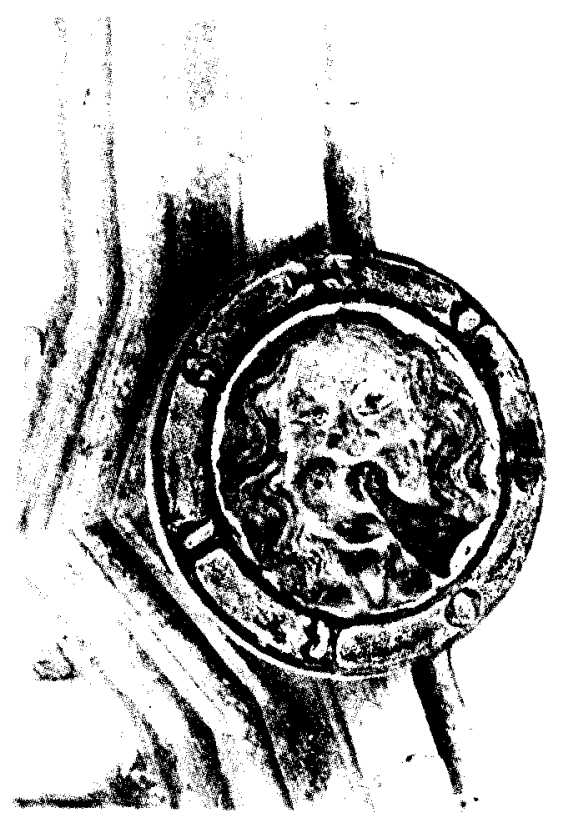

Fig. 9. Viento Chorus. 